\title{
Anaplastic Large Cell Lymphoma Occurring in an HIV-Positive Patient
}

\author{
Philippe Genet, Driss Chaoui, Virginie Masse, Ahmad Al Jijakli, \\ Nina Arakelyan, and Laurent Sutton
}

Service d'Hématologie, Centre Hospitalier Victor Dupouy, 69 Rue du Lieutenant-Colonel Prudhon,
95100 Argenteuil, France

Correspondence should be addressed to Philippe Genet, philippe.genet@ch-argenteuil.fr

Received 30 October 2012; Accepted 29 November 2012

Academic Editors: G. Feher, K. Kawauchi, and K. Nakase

Copyright (๑) 2012 Philippe Genet et al. This is an open access article distributed under the Creative Commons Attribution License, which permits unrestricted use, distribution, and reproduction in any medium, provided the original work is properly cited.

Cases of anaplastic large-cell lymphoma (ALCL) of T phenotype are sparse in the setting of HIV patients. We report herein a case of T-ALCL, with an advanced stage, pulmonary involvement, high HIV viral load, and low CD4 level. Anaplastic lymphoma kinase (ALK) protein expression was negative. Anthracyclin-based chemotherapy was unsuccessful. The literature review was performed focusing on incidence, clinical characteristics, prognosis, and physiopathology of ALCL in HIV patients. More data are needed to improve the knowledge of such cases and to define a better treatment approach.

\section{Introduction}

In the era of modern highly active antiretroviral therapy (HAART), incidence of non-Hodgkin's lymphoma (NHL) occurring in HIV patients has dramatically decreased, and even this incidence remains higher than in the general population [1-3]. NHL occurring in HIV patients has generally aggressive features. Rare cases of low-grade NHL have been described [4-6]. Histological subtypes commonly seen display a B-cell origin such as Burkitt, centroblastic, plasmablastic, or primary effusion lymphoma [1]. Nevertheless, several cases of T-cell NHL have been described $[1,7]$. We report herein a case of anaplastic large-cell lymphoma (ALCL) of T phenotype.

\section{Case Report}

A 33-year-old man was admitted in our hospital for fever. His past medical history was unremarkable. Clinical exam was normal. Because of mild abdominal pain, an abdominal CT scan was performed that revealed an extrinsic obstruction of the right ureter by lymphadenopathy. Serologic test for HIV virus was positive. A biopsy of a lymph node was proposed to the patient, but he denied any exploration and leaved the hospital.

Two months later the patient was admitted in our unit. He was febrile, and his general condition has dramatically worsened. Any peripheral lymphadenopathy was detected. A new CT scan revealed a great increase of abdominal lymph nodes and the appearance of bilateral pulmonary nodules. CD4 cells count was $36 / \mathrm{mm}^{3}$, and HIV viral load was 366000 copies/mL. LDH was 5 times above normal values. A bronchial biopsy was performed that revealed a massive invasion by median and large histiocyte-like cells with a high mitotic index. In places, some appearances of erythrophagocytosis were seen. Between these histiocytic cells, several atypical lymphoid cells were seen. Immunohistochemical staining of these lymphoid cells showed a positivity for CD2, $\mathrm{CD} 4, \mathrm{CD} 30$, and EMA and a negativity for CD3, CD7, CD8, and EBER-1. Cytogenetic analysis was not performed, but anaplastic lymphoma kinase (ALK) protein expression was negative. The diagnosis of lymphohistiocytic variant of TALCL ALK-negative was performed. Despite chemotherapy (CHOP regimen, i.e., cyclophosphamide, doxorubicin, vincristine, and prednisone), the patient's condition worsened, 
and he died after few days from multiorgan failure secondary to a severe macrophage activation syndrome.

\section{Discussion}

NHLs occurring in the context of HIV disease are mostly of B-cell origin. Nevertheless, T-cell NHL has been described, and several data argued in favour of an increased incidence of T-cell lymphoma in HIV patients. In a cohort of 6788 HIV NHL, 1.4\% had T-cell lymphomas [7] with a relative risk of 15 above the rate observed in the general population. Another cohort of 429 AIDS-related lymphomas reported 11 cases $(2.6 \%)$ of $\mathrm{T}$ cell origin [8]. T ALCL is a rare event in the context of HIV infection. Approximately 50 cases have been reported so far [9-11]. The proportion of ALCL in HIV patients with T-cell lymphoma was $22 \%$ in a series of 51 patients reported by Castillo et al. [12], 28\% in a review of 85 patients reported by Castillo et al. [13], and $27 \%$ in a small series of 11 patients reported by Arzoo et al. [8].

ALCL in HIV-negative and -positive patients shares several common clinical features. An advanced disease (stage III or IV) was observed in the great majority of patients $[9,10]$. Extranodal involvement is common. As for our patient, pulmonary involvement is present in $25 \%$ of cases.

In contrast, molecular signature of ALCL, that is, $t(2$; 5)(p23; q35), seems to be more frequent in HIV-negative ALCL (about half of the patients reported [14]) and low in HIV-positive ALCL $(0-11 \%)[9,12]$. This translocation induces a fusion between the nucleophosmin (NPM) gene on chromosome $5 \mathrm{q} 35$ to ALK gene on $2 \mathrm{p} 23$ leading to the activation of ALK. Other translocations implicating ALK have been described such as $t(1 ; 2)(\mathrm{q} 21 ; \mathrm{p} 23), t(2 ; 3)(\mathrm{p} 23$; $\mathrm{q} 21)$, and $t(2 ; 17)(\mathrm{p} 23 ; \mathrm{q} 23)$. ALK is then fused to another gene partner than NPM [14].

Regarding the prognosis of ALK expression, conflicting data have been reported in HIV-negative ALCL patients. ALK expression is generally considered as a favourable criterion. In a recent series of 138 HIV-negative ALCL patients, any prognostic impact of ALK expression was seen in multivariate analysis [15]. The apparent poor prognosis of ALKnegative was explained by the more aggressive features and more advanced International Prognosis Index [15]. Prognosis of HIV-positive ALCL is generally very poor. In a review of 32 and 24 published cases, median survival was only 5 months and 6 months, respectively $[9,13]$. In the review by Castillo et al., a majority of these patients received a CHOP regimen. The most common causes of death were lymphoma progression (37\%) and opportunistic infections (31\%) [9].

Data on physiopathology of HIV-positive ALCL are very poor. As we mentioned before, rearrangement of ALK gene seems to be very rarely implicated. HHV-8 has not been associated with HIV ALCL [9]. EBV was detected only in a minority of cases.

In conclusion, ALCL in HIV patients is a rare event. Prognosis is often very poor with standard treatments. So, alternative approaches must probably be used. Intensive chemotherapy with autologous stem cell transplantation could be an interesting approach, since a recent survey published by the EBMT has demonstrated identical results for
HIV-positive patients and HIV-negative patients with this procedure $[16,17]$. The experimental anti-CD30 antibodydrug conjugate (brentuximab vedotin) has given promising results in HIV-negative ALCL [18] but, to our knowledge, has not been tested in HIV patients.

\section{References}

[1] W. H. Navarro and L. D. Kaplan, "AIDS-related lymphoproliferative disease," Blood, vol. 107, no. 1, pp. 13-20, 2006.

[2] C. Besson, A. Goubar, J. Gabarre et al., "Changes in AIDSrelated lymphoma since the era of highly active antiretroviral therapy," Blood, vol. 98, no. 8, pp. 2339-2344, 2001.

[3] M. Hleyhel, A. Belot, A. M. Bouvier et al., "Risk of AIDSdefining cancers in HIV-1-infected patients (1992-2009). Results from FHDH-ANRS CO4," in Proceedings of the 11th International Congress on Drug Therapy in HIV Infection, Glasgow, UK, November 2012.

[4] A. M. Levine, S. Sadeghi, B. Espina, A. Tulpule, and B. Nathwani, "Characteristics of indolent non-Hodgkin lymphoma in patients with type 1 human immunodeficiency virus infection," Cancer, vol. 94, no. 5, pp. 1500-1506, 2002.

[5] E. Boulanger, V. Meignin, M. Baia et al., "Mucosa-associated lymphoid tissue lymphoma in patients with human immunodeficiency virus infection," British Journal of Haematology, vol. 140, no. 4, pp. 470-474, 2008.

[6] P. Genet, D. Chaoui, C. Fourcade et al., "Splenic marginal zone lymphomas with villous lymphocytes in HIV-patients," Leukemia and Lymphoma, vol. 54, pp. 181-183, 2013.

[7] R. J. Biggar, E. A. Engels, M. Frisch, and J. J. Goedert, "Risk of T-cell lymphomas in persons with AIDS," Journal of Acquired Immune Deficiency Syndromes, vol. 26, no. 4, pp. 371-376, 2001.

[8] K. K. Arzoo, X. Bu, B. M. Espina, L. Seneviratne, B. Nathwani, and A. M. Levine, "T-cell lymphoma in HIV-infected patients," Journal of Acquired Immune Deficiency Syndromes, vol. 36, no. 5, pp. 1020-1027, 2004.

[9] K. Perez, J. Castillo, B. J. Dezube, and L. Pantanowitz, "Human immunodeficiency virus-associated anaplastic large cell lymphoma," Leukemia and Lymphoma, vol. 51, no. 3, pp. 430438, 2010.

[10] V. E. Nava, P. Cohen, M. Kalan, and M. Ozdemirli, "HIVassociated anaplastic large cell lymphoma: a report of three cases," AIDS, vol. 22, no. 14, pp. 1892-1894, 2008.

[11] S. Kumar, A. Wanchu, A. Sharma et al., "Spinal cord compression caused by anaplastic large cell lymphoma in an HIV infected individual," Journal of Cancer Research and Therapeutics, vol. 6, no. 3, pp. 376-378, 2010.

[12] J. Castillo, B. E. Beltran, M. Bibas et al., "Prognostic factors in patients with HIV-associated peripheral T-cell lymphoma: a multicenter study," American Journal of Hematology, vol. 86, pp. 256-261, 2011.

[13] J. Castillo, K. Perez, C. Milani, B. J. Dezube, and L. Pantanowitz, "Peripheral T-cell lymphomas in HIV-infected individuals: a comprehensive review," Journal of HIV Therapy, vol. 14, no. 2, pp. 34-40, 2009.

[14] H. M. Amin and R. Lai, "Pathobiology of $\mathrm{ALK}^{+}$anaplastic large-cell lymphoma," Blood, vol. 110, no. 7, pp. 2259-2267, 2007.

[15] D. Sibon, M. Fournier, J. Brière et al., "Long-term outcome of adults with systemic anaplastic large-cell lymphoma treated within the groupe d'etude des lymphomes de l'adulte trials," Journal of Clinical Oncology, vol. 30, pp. 3939-3946, 2012.

[16] P. Balsalobre, J. Díez-Martín, A. Re et al., "On behalf of the 
EBMT Lymphoma Working Party. The European experience on Autologous Stem Cell Transplantation in HIV-related lymphoma patients: An EBMT Lymphoma Working Party analysis," Journal of Clinical Oncology, vol. 27, pp. 2192-2198, 2009.

[17] P. Balsalobre, J. Berenguer, P. Miralles et al., "Conventional chemotherapy followed by consolidation with autologous hematopoietic transplantation $V s$ chemotherapy alone in $\mathrm{HIV}+$ patients with Large B Cell Lymphoma (LBCL) in first Complete Remission (CR). A retrospective analysis on behalf of the EBMT lymphoma working party and the GESIDA/ PETHEMA registry of HIV+ patients with Non-Hodgkin's Lymphoma (NHL)," in Proceedings of the 51st ASH Annual Meeting, New Orleans, Lo, USA, December 2009.

[18] A. P. Skarbnik and M. R. Smith, "Brentuximab vedotin in anaplastic large cell lymphoma," Expert Opinion on Biological Therapy, vol. 12, pp. 633-639, 2012. 


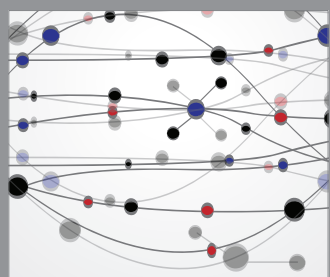

The Scientific World Journal
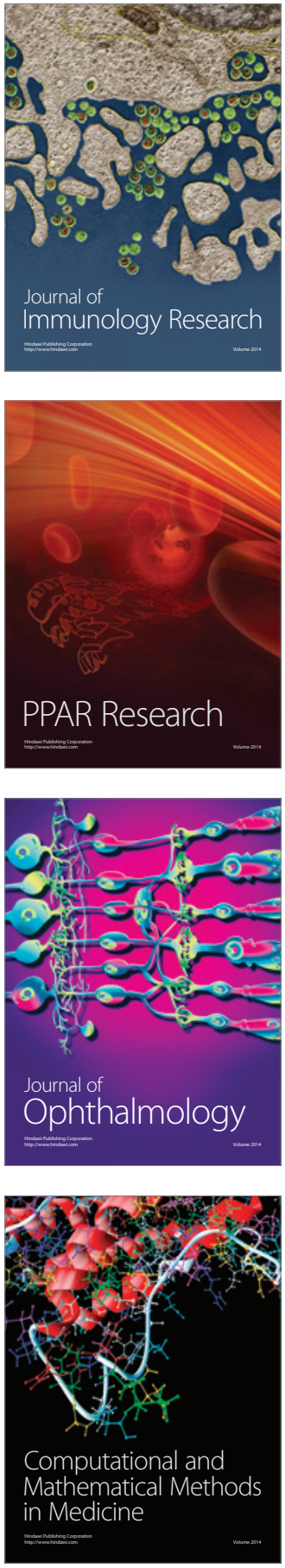

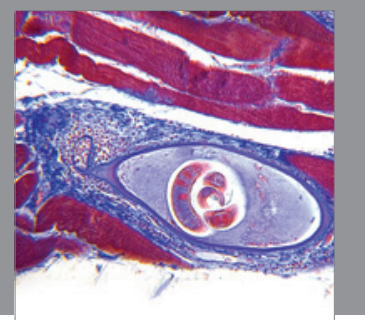

Gastroenterology

Research and Practice
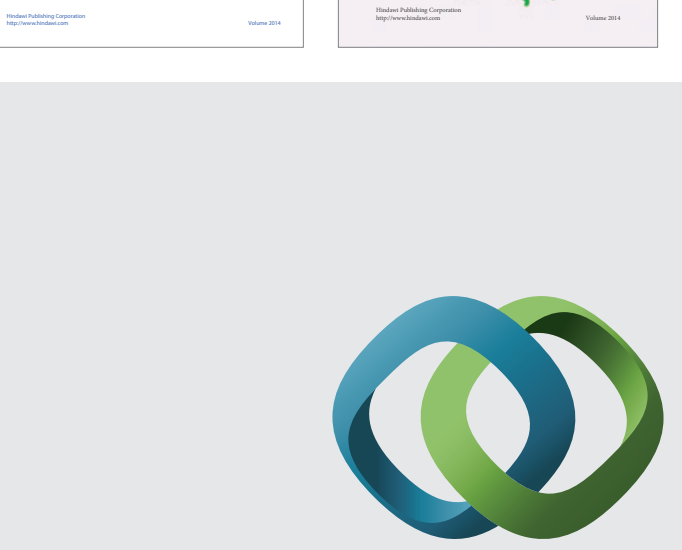

\section{Hindawi}

Submit your manuscripts at

http://www.hindawi.com
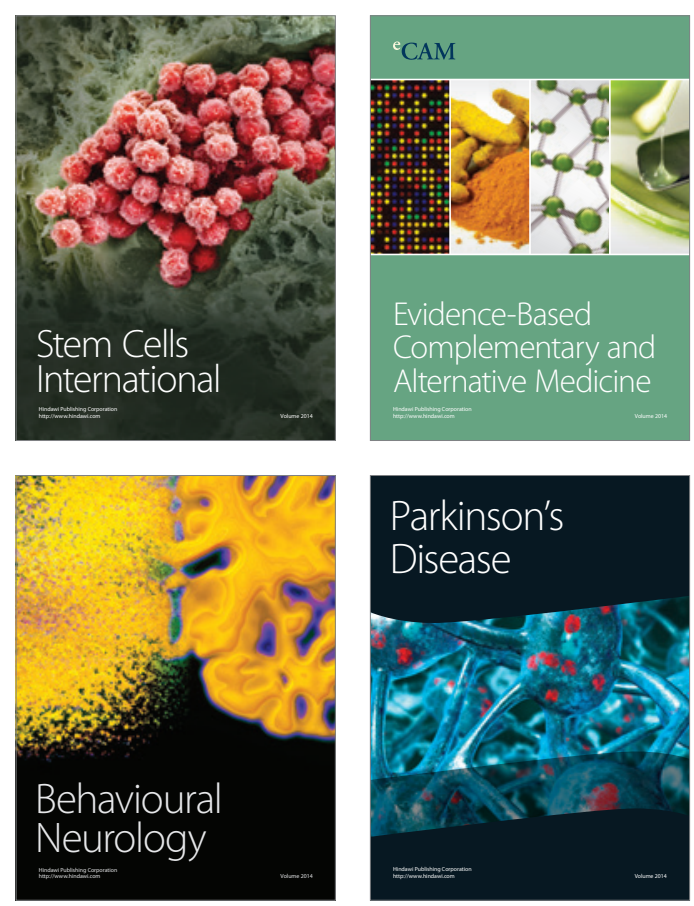

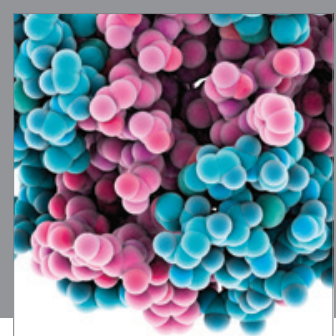

Journal of
Diabetes Research

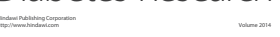

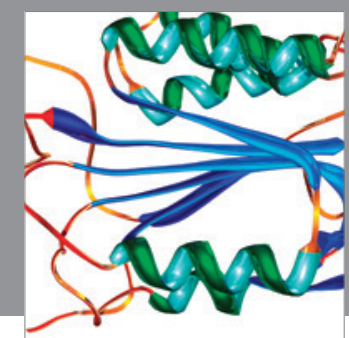

Disease Markers
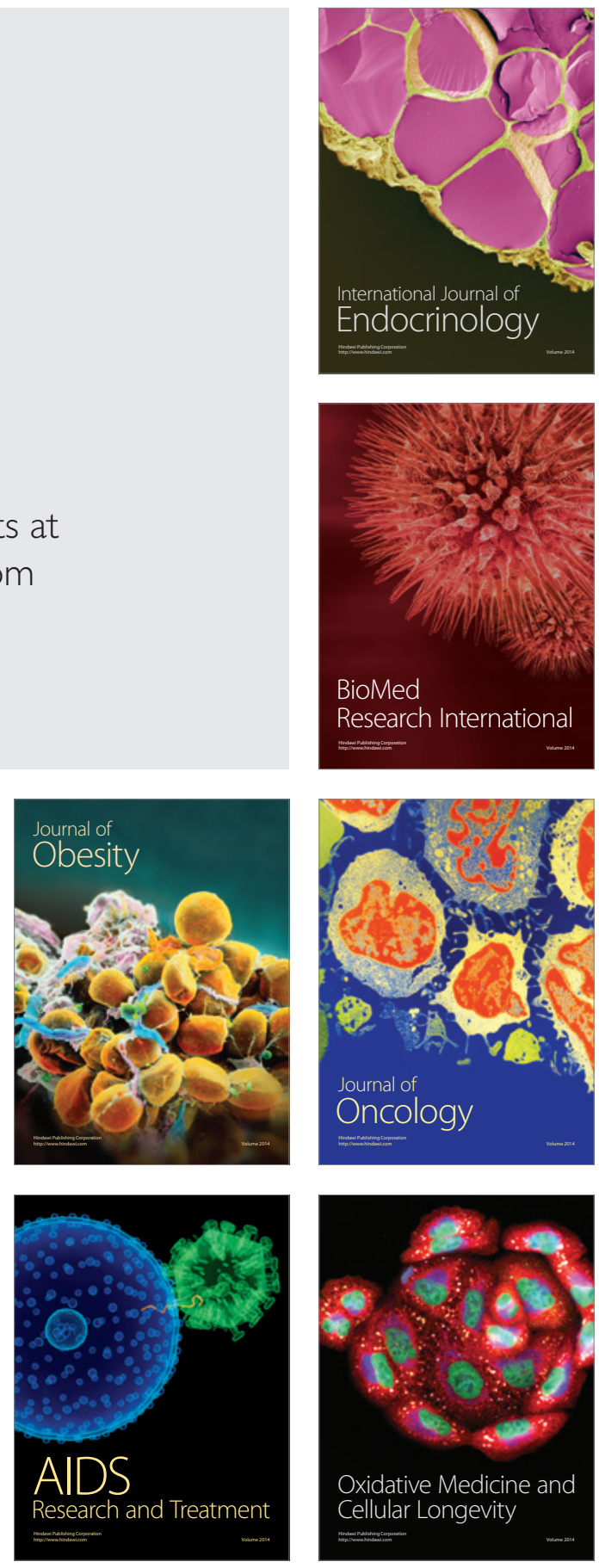